\title{
Making Ideas Work: Obstacles for Successful Translation of the Integrated Approach of IT Management
}

\author{
HANS DOOREWAARD AND MARK VAN BIJSTERVELD
}

Nijmegen Business School, Faculty of Policy Sciences, University of Nijmegen, P.O. Box 9108, NL-6500 HK Nijmegen, The Netherlands

\begin{abstract}
In the early 1980s a user-organization-oriented approach of IT management came forward focusing on both the integration of technological and organizational systems design and participatory organizational transformation, with special attention to user involvement. The integrated approach never settled down solidly. To intrude the mainstream managerial discourse, the integrated approach of IT management is presented as a seductive concept, promising to solve experienced difficulties of the former technology-led approach. But, paradoxically, the strength of its rhetoric is the weakness of its application, due to problems in the translation of promising core ideas into day-to-day practices of IT development. Translation is not just a matter of rational calculation. Translation often takes place unintentionally, as part of an ongoing and power-based process of implicit meaning formation. Hence, the translation of promising core ideas is always subject to the influence of slowly changing (implicit) power processes in organizations. Based on a conceptual model of translation processes, we detect major translation obstacles, as critical factors of success, in the introduction, adoption, and implementation of the integrated approach of IT management. We illustrate this process analyzing development and applications of the integrated approach of $\mathrm{TT}$ management in a large
\end{abstract} bank.

Success and failure of IT management; Technological and organizational redesign; Management fashion; Translation theory

\section{INTRODUCTION}

Neglecting organizational and social aspects of IT development and implementation is considered a major background of experienced difficulties of IT management. Hence, in the past decades user-organization-oriented approaches have been developed in order to improve IT management performance. The integrated approach of IT management came forward in the early 1980 s as a new and promising approach, better equipped to deal with problems in developing, implementing, managing, and maintaining IT systems than the prevailing technology-led approach. The approach focuses on:

- the integration of technological and organizational systems design;

- participatory organizational transformation, with special attention to user involvement.

The approach is promising, because its proponents claim higher organizational performance leading to both higher effectiveness/efficiency and higher quality of working life. However, despite its promises and the good intentions of all involved, the integrated approach has never settled down solidly. In many occasions the approach does not reach beyond the level of experimenting, there-

Correspondence and requests for reprints should be addressed to $\mathrm{Dr}$. J. A. C. M. Doorewaard. Tel: 31-24 361 2332/2028; Fax: 31-24 361 1933: E-mail: H.Doorewaard@BW.KUN.NL by not significantly improving the outcomes of IT management practices.

The purpose of this article is to analyze experienced difficulties in the practical application of the integrated approach of IT management, emphasizing critical factors of success in the translation (Latour, 1986; Røvik, 1996,1998 ) of its promising ideas into day-to-day-practices of IT management in organizations. We do not analyze the potential of new techniques to develop, implement, manage, and maintain IT systems successfully. Our analysis teaches us more about success and failure of IT management approaches and less about the success and failure of the systems themselves. As we will argue in this article, crucial difficulties in the translation of its core ideas into successful practices are related to the integrated approach being an application of a management fashion and therefore suffering from the effects of the so-called fashion paradox.

\section{The Fashion Paradox}

A management fashion can be described as a more or less coherent, prescriptive set of ideas of organizational (re)design which gained broad popularity during a certain period of time (Benders \& Van Bijsterveld, 1998). Management fashions are blessed with an "aura of success." The new, inspiring, and promising concept is marketed as the one and only solution for current organizational problems. To successfully disseminate its core 
ideas, a rhetorical campaign is launched by management fashion setters, often management gurus and consultancy organizations (Abrahamson, 1996). In order to make the new concept appealing for a broad audience it is presented as a set of simple, universal, and noncontroversial ideas which therefore are highly general and ambiguous (Brunsson, 1993). It is this ambiguity of the concept that makes it useful in a broad variety of organizations in distinct branches of industry and in different countries. In order to create the "aura of success" the discourse focuses on the attractiveness of the promised organizational benefits without giving a detailed presentation of the pros and cons of its tools. These promises encourage organizations to start up change projects under the banner of the new concept. However, promises are not practices. Hence, in practice many organizations experience great difficulties in translating promising ideas to make the new concept function properly. It then becomes clear that the adopted set of ideas is far from being a set of elaborated management tools and that in day-to-day-reality the application cannot live up to all of the rhetorical promises of the concept. Confronted with the limits of the approach, actors involved (management, users, IT professionals) become disillusioned and start searching again for another concept that may provide a better answer to experienced problems. Seemingly, the rhetoric used during the dissemination of a management fashion is in contrast to the reality of its application. Looking closer, however, it will be evident that overstated promises are part of the reality of the dissemination of a management fashion. Without a promising rhetoric the new concept would never have been spread out into the managerial discourse and subsequently would never have been introduced in the organization at all. Paradoxically, the strengths of the rhetoric of a management fashion form the weaknesses of its application. Hence, promising concepts are not enough; in order to implement the new approach successfully it is needed to pay attention to the obstacles in translating its core ideas into practice.

\section{Structure}

This article is structured as follows. First, we describe the promises of the integrated approach of IT management. Then we introduce our model to analyze translation obstacles, based on Weick's (1979) organizing model and Røvik's $(1996,1998)$ theory of translation. After a short presentation of the research methodology, we analyze the translation problems organizations face in implementing newly developed methods and tools. We illustrate our analysis by exploring problems in the introduction, adoption, and implementation of PROMIS, the integrated approach of IT management in a large bank. Despite its promising perspective, PROMIS failed to materialize its core ideas, due to fashion-related problems. What happened to PROMIS might be an illustration of the life cycle of other applications of the integrated approach of IT management. We conclude this article with a discussion of the impact of the fashion paradox in introducing new ideas of IT management in organizations.

\section{THE INTEGRATED APPROACH OF IT MANAGEMENT: A PROMISING CONCEPT}

Scientific research reporting of failing IT projects is widespread (see, e.g., Avison \& Wood-Harper, 1991; Beath \& Orlikowski, 1994; Clegg, Chris, et al., 1996; Clegg \& Kemp, 1986; Dunlop \& Kling, 1991; Homby et al., 1992; Jenkins, Naumann, \& Wetherbe, 1984; Jones, 1986; Lucas, 1975; Martin \& McClure, 1983; Saarinen \& Sääksjärvi, 1992; Sauer, 1993; Symon \& Clegg, 1991; Zelkowitz, Shaw, \& Gannon, 1979; for an extended overview see Sauer, 1998). Despite the long time span and the differences in national and cultural background of the analyzed IT projects, all studies come to the same, rather pessimistic, conclusion. The majority of IT investments do not meet their performance objectives and the majority of new systems are delivered late and over budget (Clegg et al., 1996).

Analyzing the difficulties in producing adequately functioning IT systems in time and within the limits of budget, research questions the paradigms of the prevailing-technology-led-approach of IT management. Within this paradigm (Orlikowski, 1992), IT development is seen solely and only as a matter of building new systems and developing new hardware and software. Organizational aspects (job redesign, required qualifications) are assumed to follow the constraints of the selected and developed technology. Such one-dimensional approach of IT management is widely considered ineffective and inefficient (see, e.g., Bjerknes, Ehn, \& Kyng, 1987; Clegg et al., 1996; Friedman \& Cornford, 1989; Greenbaum \& Kyng, 1991; Salzman \& Rosenthal, 1993; Scarborough \& Corbett, 1992; Van Bijsterveld, 1997). Hence, in the wake of emerging new paradigms on technological and organizational change (e.g., strategic choice models, the structural model of technology) (Markus \& Robey, 1988; Orlikowski, 1992; see also Scott Morton, 1991), new techniques and methods are developed to deal with the problems of the technologyled approach. The new perspective strongly emphasizes a so-called integrated approach of IT management, stressing the need to integrate technological and organizational development and to stimulate user participation in decision-making processes (Bjerknes et al, 1987; Borum \& Kristensen, 1989; Doorewaard \& Regtering, 1990; Ehn, 1988; Floyd \& Keil, 1983; Greenbaum, 1979, 1995; Greenbaum \& Kyng, 1991; Hirschheim, 1985; Mathiassen, 1984; Mumford, 1983; Scott Morton, 1991; UTOPIA PROJECT, 1982; Williams, 1987; Zuboff, 1988).

Although the promises of the integrated approach of 
IT management are widely discussed, its content is hardly ever defined exactly. The integrated approach exposes itself as a management concept. Hence, the approach is less a particular elaborated set of tools, and more a general and vague, but attractive and appealing, perspective on IT management. The approach promises to solve the problems of the technology-led approach by integrating four domains of activities concerning redesign and organizational change (Doorewaard \& Knudsen, 1992; Doorewaard \& Regtering, 1990). The dimension of redesign includes both the domain of the integrated diagnosis of critical factors of success and the domain of the integration of technological and organizational systems design. The dimension of organizational change focuses on the domain of strategic orientation and the domain of participatory organizational transformation. Figure 1 presents the four domains.

First, the integrated approach of IT management stresses the importance of a strategic orientation aiming at mutual adjustment of the overall corporate strategy and the strategic options of technological and organizational change. This adjustment is crucial, because IT development changes organizations' vital functions and thus influences organizational performance outcomes in a crucial way, evoking adjustments in decision-making structures, work and information flows, communication patterns, and so on. Next to the mutual adjustment of IT strategy and corporate strategy, strategic orientation focuses on consensus between all parties involved (management, staff, IT experts, end-users) with regard to the way organizational and technological goals will be achieved.

Second, meticulous project diagnosis is stipulated in order to detect critical factors of project success at an early stage. Integrated project diagnosis (e.g., SBA, 1984) stresses the need of a scrupulous analysis of all relevant conditions for success. These critical conditions are related to both technological components (hardware, software, infrastructure) and organizational constraints,

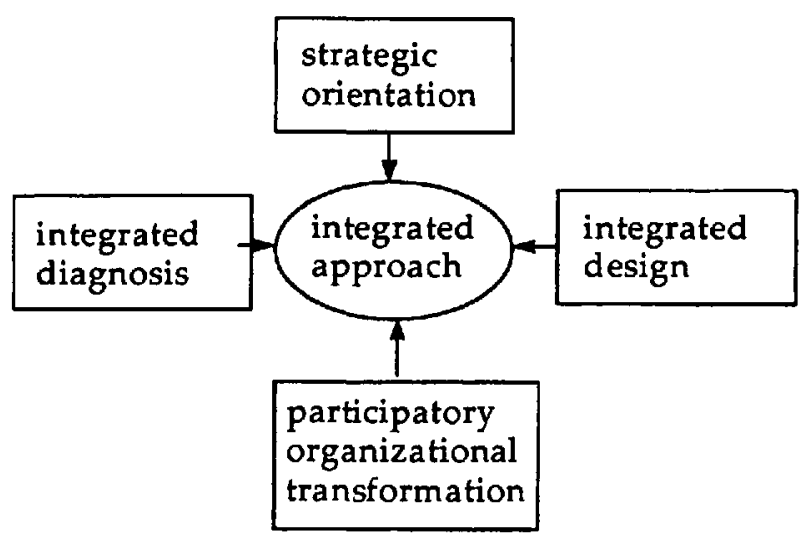

Figure 1. Four domains of the integrated approach of IT management. such as organizational environment, organizational structures and (sub)cultures, and the power and interests of parties involved.

Third, the integration of technological and organizational systems design emphasizes the interrelation between technical design, organizational design, and project control. The technology-led methodology designs internally consistent IT systems, relatively isolated from their implementation in user organizations. Such focus is known to be ineffective, ignoring the mutual impact of organizational and technological change (Beath \& Orlikowski, 1994; Clegg \& Kemp, 1986; Homby et al., 1992): "the systems works but it does not fit in our organization." Hence, the integrated approach of IT management focuses on organization-oriented system development methodology, in which experienced problems in business processes steer the development of IT solutions (e.g., Checkland, 1981; Checkland \& Holwell, 1998; Ehn, 1988; Greenbaum \& Kyng, 1991; Taylor, 1990; UTOPIA PROJECT, 1982). Additionally, because new IT developments and solutions are considered enabling factors of organization redesign, they have to be taken into account in an early stage of organization development (Hammer \& Champy, 1993). To control the integrated project, the approach focuses less on exact calculation of costs and benefits, because IT costs and benefits appear hard to detect and measure. Hence, newly developed tools focus on increasing project control by estimating risks and uncertainties with regard to project environment, project aim, and project methodology (e.g., Dreger, 1989; Putnam \& Myers, 1992).

Fourth, second generation organization development focuses on participatory organizational transformation (Cummings \& Worley, 1997; French \& Bell, 1995) criticizing the planned change vision of technology-led IT approaches. Basically, the planned change approach is linear, project oriented, and expert based (Zaltman \& Duncan, 1977). These characteristics, however, often turn out to be hidden pitfalls, obstructing successful organizational change (French \& Bell, 1995). Like many other organizational transformation processes, IT development is not a linear process, but characterized by iteration: "two steps forward, one step back" (Cummings \& Worley, 1997). Participatory organizational transformation stresses the need of both user involvement and a multifunctional project management team. Insufficient user involvement in decision-making processes is considered an important background of a failing technology-led approach (Clegg \& Kemp, 1986). Insufficient incorporation of user knowledge in the newly developed systems causes both nonacceptance and resistance to technological change and inadequate functioning of IT systems (Blackler \& Brown, 1986). Hence, so-called cooperative or participatory design approaches (see Avison \& Wood-Harper, 1991; Bødker, 1991; Greenbaum \& Kyng, 1991) encourage active end-user participation (e.g., in prototyping) and a facilitating role 
of IT staff, while user organization management is supposed to have final project responsibility. Further, the integrated approach emphasizes the need of a project management team, enabling user management, end-users, and the IT experts to bring the ideas of participatory design into practice. Hence, so-called multifunctional project teams are presented, consisting of technological and organizational experts as well as end-users. In mutual adjustment this team is responsible for the integrated design and development of the new system.

At first glance the integrated approach of IT management is promising. While disseminating the core ideas, its proponents emphasize how the new approach might deal successfully with traditionally experienced problems of the technology-led approach, like malfunctioning IT systems, exceeding budgets, missing deadlines, misfit with organizational processes, user resistance to implementation, and so on. However, despite the promising paradigmatic evolution, apparently little has changed in the day-to-day-practices of development, implementation, maintenance, and management of information technology. Recent research (e.g., Clegg et al., 1996; Sauer, 1998; Van Bijsterveld, 1997) does not find indications of significant improvement in the practice of IT management due to the dissemination and application of the new approach. Although the integrated approach successfully seems to intrude the dominant IT-management discourse (all persons involved stress upon the importance of the realization of its core ideas), in daily practice the technology-led approach is still dominant. Hence, many IT projects suffer from a so-called satisficing strategy (Symon \& Clegg, 1991): difficulties in implementing the integrated approach lead to acceptation of a less optimal integrated solution and to a pragmatic attitude to deliver "at least a technical system that works."

\section{A MODEL TO ANALYZE TRANSLATION OBSTACLES}

Assuming that the approach is able to deal successfully with hardware and software problems, why it so difficult to realize the core ideas of the integrated approach of IT management in practice? Answers to this question might be found, for example, by comparing the feasibility of both the technology-led and the integrated approach, or by an historical analysis of the integrated approach as stage in an ongoing process of IT management evolution. In this article we analyze difficulties in realizing the integrated approach from a translation theory perspective, which provides us with additional insights focusing on the integrated approach of IT management as a management fashion.

Translation is "[T]he spread in time or space of anything-claims, artifacts, goods-in the hands of people; each of these people may act in many different ways, letting the token drop, or modifying it, or deflecting it, or betraying it, or adding to it, or appropriating it" (Latour in Røvik, 1998, p. 267). When new management concepts enter an organizational discourse, a management of meaning and identity is activated, aiming at the (re)construction of a shared interpretation via a process of spotting and breaking down old interpretations, and reshaping new and alternative meanings (Weick, 1979). Meaning and identity formation processes are temporary, slowly changing "fixities" (Clegg, 1989), in which dominant basic assumptions, norms, and values rule. During these processes general and appealing management recipes are being translated and modified in order to fit the features of a particular organization. Sometimes popular organization concepts are translated as a result of rational calculation (Røvik, 1998), but in many other occasions translation is an unintended and concealed, yet power-based, process. Translation often occurs in "Bourdieuan" fields (Bourdieu, 1977): actors operate in nonneutral, value, and power-based organizational contexts, in which, in an ongoing and implicit way, ever-changing meaning and identity formation processes take place as chains of related (re)formulations, ladders of (re)interpretations, and slowly changing norms and values. The implicitness of power-based translation requires a specific theoretical view on power, which does not only pay attention to manifest power (authority or manipulation) but also to so-called hegemonic or implicit power processes (Benschop \& Doorewaard, 1998; Clegg, 1989). Hegemonic power processes express the casualness with which many people in many circumstances of daily life wield power or are subjected to power, without being always fully aware of this form of influence (Doorewaard, 1988). Translation, as a process of ongoing and selective meaning and identity formation, is always part of this slowly changing constellation of manifest and latent power processes in organizations. Different groups involved redefine and translate general notions (un)intentionally in such a way that implementation of the new concept promises to support their particular interests and wishes.

Analyses of IT cases (Clegg et al, 1996; Symon \& Clegg, 1991; for a recent overview see Sauer, 1998) clearly indicate the impact of translation obstacles. Apparently, in many occasions, development and implementation problems (like malfunctioning systems, miscommunications between several groups of actors and users' resistance to changing IT projects) do not stem from technical problems nor from the lack of good will or inadequate qualities of employees, but result from underestimating the difficulties in translating promising ideas into day-to-day-practices. To gain insight into these translation obstacles a conceptual model is needed. For the purpose of our article and referring to the management fashion literature (see, e.g., Abrahamson, 1996, 1997; Kieser, 1997; Latniak, 1995; Orlikowski, 1992; Ramsay, 1996), we developed a simple, conceptual model of translating processes, based on Weick's (1979) 
“organizing" model and Røviks's $(1996,1998)$ theory of translation (see Fig. 2). We use this model to present a structured insight into occurrence, visibility, and impact of the main translation problems and, thus, into critical factors of success in the phases of introduction, adoption, and implementation of promising ideas in practice (Abrahamson, 1996; Benders \& Van Bijsterveld, 1998; Van Bijsterveld, 1997).

A first translating activity takes place in the introduction phase, when the new management fashion enters the organizational discourse. Management fashion setting is "the process by which management fashion setters continuously redefine both theirs and fashion followers" collective beliefs about which management techniques lead rational management progress" (Abrahamson, 1996, p. 257). In this introduction process a supply and demand side can be distinguished. On the supply side new concepts are invented, further processed, and disseminated by management gurus or specific knowledge-based organizations (e.g., business schools and management consultants). Their ideas differ in consistency and vagueness: "some vague ideas allow a lot of room for each individual organization to give them its own interpretation. Other institutionalized standards, however, provide more detailed prescriptions for how organizational activities should be carried out" (Røvik, 1996, p. 142). Nevertheless, successful dissemination of a management concept largely depends on the attractiveness of its rhetorical presentation. On the demand side the success of the new concept depends on the extent to which those, who form the new concept target group (management and staff), actually accept this concept as a plausible one. For this plausibility to occur, the ideas most likely to prevail are those that are apprehended as capturing the "Zeitgeist" or "the spirit of the time" (Grint, 1994). Successful adjustment between supply and demand of promising management concepts takes place in the form of an enactment process. Based on past experiences and dominant cognitive schemes or interpretation structures (Van Bijsterveld, 1997), the adopting organization isolates, of all possible new management concepts and ideas that are being offered, the most promising one as possible solution for its problems. Hence, during the introduction phase, successful translation of the core ideas of the integrated approach requires the "enactment click." Enactment is part of a management of identity (Røvik, 1998), a process through which newly introduced ideas are being reformulated in order to fit in the existing and recognizable organizational discourse. As part of a power process, successful translation enacts core ideas of the new approach to the organizational perspectives of dominant parties in the organization.

When the new approach is introduced and enacted, several activities take place concerning the adoption of the new approach in the organization. Successful adoption takes three major steps in translating the new concept into practice. First, the concept has to be accepted as the one and only solution for experienced problems. Research suggests that organizations intentionally or unintentionally accept a new concept to improve effectiveness and efficiency, for gaining legitimization, and to seduce other organizations to follow their footsteps (Astley \& Zamutto, 1992; Brunsson \& Olsen, 1993). The general, vague, and noncontroversial form in which the new concept is usually disseminated provides the concept with a certain amount of interpretative flexibility (Orlikowski, 1992) of viability (Ortmann, 1995), which makes it useful, applicable, and acceptable for all of these purposes. As part of a power process, successful acceptance requires such a translation of the new concept that it will fit within the interests and wishes of dominant organizational parties. Second, a complex process of (re)interpretation takes place. Actors select partial arguments and lines of reasoning of the new managerial concept and make plausible interpretations of its presumed contents to remove the original equivocality and vagueness. Interpretation can take many forms. Actors reformulate ideas by concretizing vague notions to fit the existing organizational practice, by imitating stories of success, and by combining or remolding several new recipes into a new one (Røvik, 1998). Successful (re)interpretation takes place in accordance to the existing power constellation in the organization. Third, the

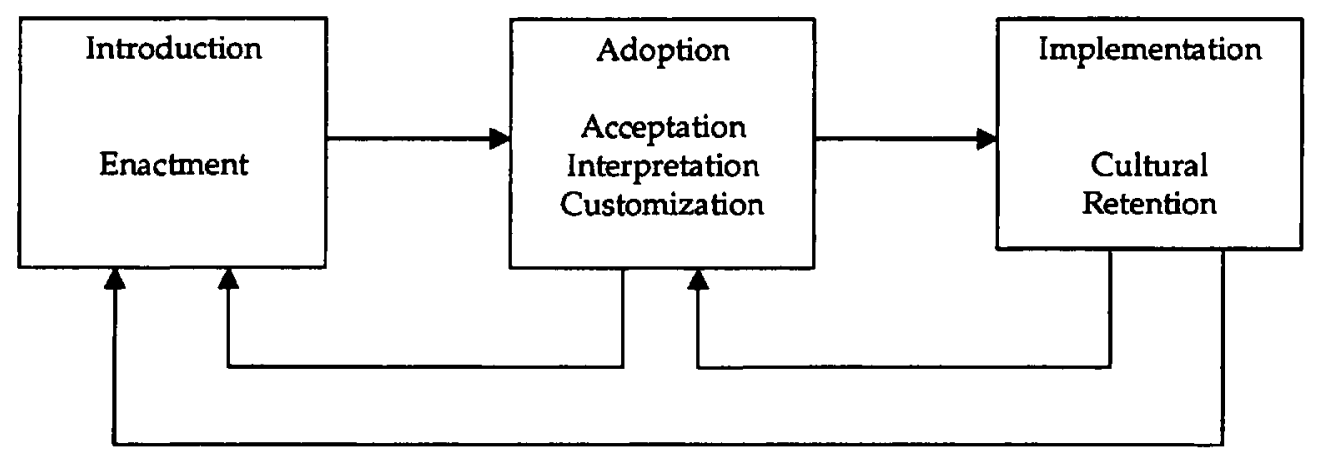

Figure 2. Translation processes in introduction, adoption, and implementation of management concepts. 
concept has to be operationalized in new procedures and activities. A complex translating machinery will be energized in order to "customize" the concept to make it fit the local organizational structure and culture in the user organization (Borum \& Westenholz, 1995). Only then the adopted loosely coupled set of ideas is developed into a meaningful prescription (Røvik, 1996). Customization does not only take place in a technical, but most of all, in a cultural sense, to make sure that the new concept "matches the wallpaper of the organization." Hence, successful adoption requires translation into a general acceptance, commonly shared interpretations, and a one-dimensional cultural customization. When translation is unsuccessful the organization might "loop backwards": the organization drops the new concepts and turns back towards the introduction phase, looking for another promising concept.

In the third phase of implementation a successful retention of the new set of managerial ideas takes place. Translation in this phase is primarily oriented on the fixation of the new set of ideas in the organizational culture. The implementation of new organization concepts demands changes in organizational behavior and the dominant way of thinking and perceiving. Such a change is a difficult and risky undertaking. Cultural change has to pay attention to processes of "unfreezing" and "freezing" (Lewin, 1951). Unfreezing emphasizes the importance of both communis opinio concerning the need of change and a flexible, open, critical, and reflective attitude of the organization members involved. Freezing stresses the importance of the consolidation of newly developed concepts, so that it will become an integrated part of the organization's vision, strategy, structure, and culture. Like in the first two phases of introduction and adoption, the success of translation in this phase depends on the extension of political support for the planned cultural changes. Failing cultural change might force the organization to a renewal of the adoption process or even to start all over again.

Actual implementation does not stop the ongoing process of translating management concepts. Applications of the new concepts are always temporarily fixations. In use, the concept continuously will be shaped and reshaped (Orlikowski, 1992; Ortmann, 1995) according to individual or group interests and goals.

\section{METHODOLOGY AND BACKGROUND}

In order to analyze main problems and critical factors of success in the translation of the integrated approach of IT management profoundly, we carried out an empirical research focusing on distinct barriers implementing the integrated approach of IT management. Between September 1996 and March 1997 a cases comparative study on the management of IT projects in a large bank was conducted. The complexity of our research object-the cartography of a multiple set of factors and circum- stances influencing the success of the integrated approach-and its explorative and descriptive nature call for a qualitative research strategy, which does not allow general conclusions. Our research strategy, however, benefits from insights acquired from in-depth analyses, characteristic for a cases comparative approach (Yin, 1989). Data are collected through a combination of techniques. We analyzed internal documents, made personal observations of development and implementation of IT systems, and held approximately 40 open interviews with IT experts, managers, end-users, and HRM staff. Our research is based on analyses of both the process of designing PROMIS (the application of the core ideas of the integrated approach of IT management) and two IT projects, designed and implemented according to the newly designed integrated PROMIS methodology.

PROMIS is an application of the integrated approach of IT management in many ways. Analyzing the handbook of PROMIS and several documents prepared to introduce PROMIS in the bank (Van Bijsterveld, 1997) we notice that-in theory-the approach encompasses all four domains of the integrated approach of IT management, mentioned earlier in this article. Attention has been paid to the strategic orientation (PROMIS is user organization oriented and embedded in the corporate strategy). PROMIS highly estimates integrated project diagnosis and focuses on the integration of organizational and technical (re)design. Explicitly, PROMIS stipulates the importance of user involvement and is based on participatory organizational transformation. Nevertheless, as we will argue in the remainder of this article, we found that despite this perspective PROMIS failed to materialize the core ideas of the integrated approach in the daily practices of developing and implementing IT projects in the bank.

One major event in the recent history of the bank is important in particular, to understand the power processes that hinder the successful translation of PROMIS' core ideas into the day-to-day practice. The bank results from a recent merger. Differences in vision concerning successful IT development and implementation between the two IT departments of the merger partners have had significant influence on the discussions of the strategic assumptions of PROMIS. On the one hand, these differences force the bank to develop a sophisticated IT mission and to communicate this mission in the organization thoroughly, leading to growing insights into IT methodology and the integrated approach of IT management. On the other hand, deviancies in visions and interests constantly influence decision-making processes in developing and implementing PROMIS. In our research we came across a complex set of negotiated constituencies of several parties of both merger partners. Hence, in analyzing the translation of PROMIS in the two IT projects, we notice strong effects of power-based decision-making processes that result from strategic and cultural differences between the two merger partners. Keep 
in mind that the merger itself did not create the translation problems we describe. The postmerger situation only makes existing translation pitfalls more visible (Van Bijsterveld, 1997).

\section{TRANSLATION OBSTACLES IN INTRODUCTION, ADOPTION, AND IMPLEMENTATION OF THE INTEGRATED APPROACH}

We analyze main translation obstacles hindering the successful fulfillment of translation requirements regarding enactment, acceptation, interpretation, customization, and cultural retention of the new approach. This analysis offers us insight into the main critical factors of success in the phases of introduction, adoption, and implementation of the integrated approach of IT management. "Critical success factors (-) are (-) the limited number of areas in which results, if they are satisfactory, will ensure successful competitive performance for the organization. They are the few key areas where 'things must go right' for the business to flourish" (Rockart, 1979, p. 207). Our research in the bank clearly indicates that problems implementing PROMIS do not stem from hardware or software constraints or from insufficient IT expertise. Crucial difficulties appear to be related to translating problems in the phases of introduction, adoption, and implementation of PROMIS as the new IT management approach of the bank.

\section{Introduction}

Looking at the "enactment process" in the bank it is obviously clear that the bank has made a good start. The plan to introduce and develop PROMIS, as an application of the integrated approach of IT management, is launched right on time. At the supply side, the bank is strongly influenced by consultants of a leading management consultant organization, who advocate the principles of PMC: a general approach of integrating IT and organizational development. PROMIS is developed according to the principles of PMC. At the demand side, the board directors as well as the management team sympathize with the rationality and innovativeness of the integrated approach, as criteria that constitute "good" management. In the bank the insight has been growing that it is important not just to develop better information systems but to improve business performance with the help of better information systems, which are integrated in work flow processes. IT is considered a critical success factor for the future of the new bank.

\section{One of the commercial managers stated:}

Competition in the financial sector is still growing and the profits especially for credits are very small. Several new banks and financial organizations are coming on the market. So, within the bank there is a strong urge for cost reduction and information technology is thereby seen as one of the essential tools to realize it.

Hence, the board of directors decides that the newly to develop integrated approach for IT projects must become the "collective face" of the bank on the area of information development both inwards and outwards. The handbook of PROMIS stated:

For the development, renewal or replacement of information systems on a project basis several methods were in use. The board of directors has given the order to integrate these methods into a new project management method. Goal of this method called PROMIS is to arrange the cooperation around IT projects as good as possible and to introduce one shared "project language" within the bank.

Despite the right time of launching of the concept, however, the required "enactment click" between the integrated approach and several parties in the bank stayed out. Two observations concerning translation obstacles in introduction stand out to explain why the introduction has not succeeded in connecting the new approach in the existing organizational discourse. The concept suffers from a "soft connotation" and is insufficiently supported by the main actors' external network.

Soft Connotation. The integrated approach suffers from a pejorative label. On the one hand, social aspects of IT are considered of great importance. One of the office employees states on this topic:

We do not know whether or not they are aware of the social aspect of IT projects. The division of labour is strongly influenced by the rules of banking. People have to control each other, you know, to prevent the wrong use of information and frauds. Especially older people, however, experience difficulties in adjusting to the pace of automation, but management does not pay attention to these issues.

Hence, PROMIS strongly emphasizes these social aspects of IT development. However, this emphasis apparently evokes objections from a "rational" point of view. Inherently and unintentionally, this social focus makes PROMIS being considered a "soft" concept, stemming from a noneconomic, but sociological and psychological perspective. Apparently such a qualification is a significant handicap in the dominant technological discourse of IT projects. In legitimizing PROMIS much attention is given to the "societal necessity" of the integrated approach and the importance of user participation from a democratic point of view. Too little attention, however, is paid to the presumed economical benefits and its organizational necessity. And in particular these "hard" organizational and economical benefits are supposed to steer the thinking, perception, and action of the "rational" managers in the bank.

Lacking External Network Support. An active network of external and internal influential actors support- 
ing and stimulating the spread of a concept is an essential factor in helping organization members to accept the new concept as a successful solution for organizational problems. In the bank the lack of such a supporting network is a major obstacle for a smooth and speedy introduction. Although PROMIS is molded according to the principles of an IT management approach that was widely accepted, within the bank the integrated approach is introduced as a closed off, internal bank project. Consequently, PROMIS is developed relatively isolated from the prevailing debate in the IT branch on success and failures of IT management. As a member of the team that is involved in the development of the PROMIS approach says:

Of course every organization is different and everyone makes its own demands on an approach of IT projects. It is clearly very important that the approach developed fits in the structure and culture of the organization in which it will be used. But on the other hand if we had more contact with other professionals we would not have to invent the wheel ourselves over and over again. Maybe some of the problems we had to tackle would then not have occurred. ...

Although the soft connotation and the lack of a supporting network do not obstruct the introduction of PROMIS in the bank, both factors clearly hinder a smooth enactment between the core ideas of PROMIS and the existing organizational discourse. Apparently, the only group that unconditionally embraces the new perspective is the board of directors, seduced by the perspective that PROMIS might bring about the required unification of the two merged partners. However, dominant parties of both former organizations (management, end-users, IT specialists) express a more reserved attitude towards to new approach.

\section{Adoption}

Successful adoption of an enacted new organization concept requires a broad political basis in the organization. The concept has to be accepted by key stakeholders as the one and only solution to problems experienced or opportunities perceived. To gain this approval the adopted concept has to coincide with the micropolitical interests of the stakeholders involved (Ortmann, 1995), otherwise adoption will inevitably be obstructed. That implies the need of commonly shared interpretations and a one-dimensional customization.

Analyzing adoption steps in the bank, two major translation obstacles are distinguished, preventing the development of a general adoption: insufficient internal support and the process of so-called relabeling.

Insufficient Internal Support. Within the bank internal support is considered a major prerequisite for a successful adoption of PROMIS. In order to create this support, the board decides that the project organization, responsi- ble for the development of the new approach, should consist of members from both former bank organizations. Their first task is to develop PROMIS as an instrument to give the new bank a recognizable and common face, both inside and outside the organization. However, considerable differences, both in organizational culture and in the visions on what both former partners call "an integrated approach of IT mariagement," cause problems. These differences in interpretation do not come forward explicitly, but linger on during the development process of PROMIS and, thus, implicitly hinder the emergence of communis opinio concerning the new approach. One of the project members addresses this subject as follows:

Both organizations were very different in their approach of IT projects. Our organization used to raise the whyquestion: ... "why do we do this project," while they were more focused on the how-question: ... "how do we do that project." Looking back now . . . we never really have tackled this problem, and both visions have persisted within the new approach, even though they did not match. It finally resulted in a sort of shared approach, but $I$ think it still is a way of adding up the different perspectives. ...

Insufficient attention paid to the existing differences in interpretation of "why" and "how" of the integrated approach obstructs the overall adoption of PROMIS. Discussions between IT specialists of the two former merger partners on the development of PROMIS are always influenced by latently conflicting interests and wishes and a growing distrust in each other's intentions. From the beginning a broad political basis of internal support is missing.

Relabeling. Successful adoption implies a sense-making and customization process to reach shared understanding and agreement on the exact redefinition of the distinct elements (structure, procedures, actions) of the new management concept. However, instead of one-dimensional customization we come across a frequently used process of "relabeling" in the bank. Relabeling means the reinterpretation, redefinition, and re-articulation of new concepts based on the current dominant way of thinking, perceiving, and acting. Under a new label, "old" and engraved ways of approaching IT projects are continued, a phenomenon frequently reported concerning management fashions (see Ashley \& Zammuto, 1992; Beath \& Orlikowski, 1994). We find many examples of such relabeling processes.

The semantics used to describe the new IT approach still contain many of the old, technology-focused characteristics. For example, the manual states at one place:

PROMIS is an approach for information systems development projects that are projects aimed at the development, renewal or replacement of automated information systems (emphasis added). 
However, a few lines later, when the subject of the integrated character of the approach is addressed, it is said that PROMIS:

... always, first and for all, looks for organizational solutions for organizational problems and only from then at possible IT solutions (emphasis added).

This equivocality is not just the result of inaccuracies in the manual. The former dominant technology-led approach of IT management is recognizable in PROMIS, though being relabeled with the new and attractive tags belonging to the integrated approach. Existing and familiar procedures belonging to the former IT management approaches of both merger partners are being relabeled in PROMIS. Apparently, "customization" of the core ideas of the integrated approach into PROMIS means to copy existing proceedings and to rename them as part of the new approach. Relabeling not only takes place with regard to the procedures concerning the development of IT systems. We notice the same process with regard to social and personnel aspects of IT development. The integrated approach highly values the quality of working life and emphasizes social and personnel facets. We found that-despite PROMIS' mission as an integrated approach-the detailed elaboration of PROMIS in the manual is less integrated than might be expected. The detailed instructions of the manual hardly pay any attention to activities concerning the social aspects of IT project, aspects of cultural change, and the peculiarities of the bank organization. Almost solely attention is paid to the organization and control of IT activities in a strict sense. Further, we notice that in PROMIS "social labels" are used to continue old procedures that have nothing to do with improving the quality of the working life. A financial manager gives an example of such relabeling process:

Social and organizational aspects are hardly given any attention in IT projects. On the other hand are the revenues of these projects beforehand specified as much as possible. The "P" of personnel therefore does not mean that they look for possibilities to improve the quality of working life with the project, but that they look for opportunities to cut costs by reducing personnel. The IT project is clearly driven from an economical instead of a social perspective.

Obviously relabeling does not result from intentional recalcitrance. Relabeling often takes place as a concealed process: people recognize features of familiar approaches in the new concept and will tend to interpret these new notions as well known insights as a matter of course. Relabeling shows how the adoption process is strongly influenced by current organizational culture and dominant perceptions and initiatives from the past. Relabeling, in strict sense, is a form of translation. However, this form of translation will certainly not result in a transformation of day-to-day IT management practices.

In the end, a general adoption of PROMIS has failed. Due to the lack of internal support and processes of rela- beling, the version of PROMIS, brought out by the project organization after laborious discussions, appears to be unacceptable for one of the two former bank organizations. Therefore, PROMIS is implemented in only one of the two former organizations. The mission of the board of directors, to create a shared approach, is not being realized.

\section{Implementation}

Implementing the integrated approach of IT management is less the implementation of new procedures and more the realization of a revolutionary change of mind. Unless meticulously prepared, such an organizational change process will take the form of a cultural shock for many involved. In the bank, three major translation obstacles, connected with the laborious way of changing organizational culture, prevent the successful retention of PROMIS: the top-down approach, organization culture inertia, and semantic confusion.

Top-Down. One of the developers of PROMIS stated:

It is surprising to find out that in the bank hardly any attention is given to the introduction and legitimization of PROMIS. This method is simply rammed into the organization, as we put it nicely....

This is most surprisingly in the light of the presumed unifying potential of PROMIS after the merger. Although the board of directors communicate cooperation and shared language as most important goals for developing PROMIS, the top-down practice transmits a far different message. Our analysis shows that the project management team intentionally has made the implementation the responsibility of the middle management in the user organization. Although room is made for training and support, in practice none of the middle managers request such a support: they simply implement the new approach, more or less out of the scope of the majority of the employees. One of the project managers state about this top-down approach: "they [the managers] have had their chances, but if no one is interested.. it is not our fault." Hence, although no one is to blame, the top-down implementation certainly does not help user management and end-users to embrace PROMIS as the best possible approach of IT management.

Organization Culture Inertia. Organization culture inertia makes the realization of new integrated ways of thinking and acting a slow and troublesome process (Cooper, 1994). In the bank many problems are caused by insufficient attention paid to organizational conservatism in cultural change, the difficulties in adhering the new approach within the organization, and to political and communication problems during its use. Organizational members insufficiently acknowledge that implementation of a new approach demands time, both to 
loosen the bonds with current, dominant views, norms, and routines, and to develop and establish new views, norms, and routines. In particular, the use of IT procedures and tools is known to induce a technical and instrumental attitude towards IT development, characterized by an inclination to "stick to well-known procedures" and an aversion to think creatively about new methods and tools. Orlikowski points at this inclination, quoting an IT consultant as follows: ". . . tools have definitely stopped me thinking about other ways of doing things. We bring the same mindset to the different projects, so we already know what to do" (Orlikowski, 1992, p. 417). In the bank we notice that concepts and tools in use and the mindset they represent form cultural barriers to the implementation of the PROMIS approach. Our research indicates that although IT professionals pay lip service to PROMIS, in day-to-day-practice the old routines still dominate. A complicating factor in this case is that there is no tradition in developing a shared approach:

Everyone has his own way of doing projects and it is pretty hard to let them see they really have to change. One of the problems is: they say "OK, tell me what I have to do differently!" but at the same time they keep doing the things the way they always did! Even if they would accept the new approach and the new ways of carrying out IT projects, the slightest thing will happen and they fall back to their old tools and habits.

Another indication of the underestimation of the cultural inertia in the bank is the thoughtless decision of the project organization to implement PROMIS from one day to the next. One of the IT professionals states:

\begin{abstract}
We tried to change the way of thinking and acting within the organization with a "full swing"; we tried to change it all at once and that is impossible. You can make as much noise as you want, but it doesn't work that way. I think you have to start small and slow, with a few motivated people and a few successful projects. Only after that you can make clear why the new approach does work while others fail. Then you get people interested and listening... . This approach calls for a strategic activity planning on long terms.
\end{abstract}

Semantic Confusion. Besides problems resulting from the organizational cultural inertia, problems occur in the actual use of the integrated approach. People from different departments suddenly have to work and communicate together in order to make IT project successful. The implementation of PROMIS causes communication problems, not because people involved do not want to communicate, but because they do not speak the same language. The semantics (language, ideas, and attitudes) of IT specialists are in practice clearly different from those of IT end-users or managers (Cherrington, 1989). For example, the term "user friendliness" at first face seems simple and unambiguous. However, our research in the bank suggests that different actors have different meanings of this term. When speaking of "user friendli- ness" users usually focus on quality and speed of information, while IT professionals have in mind an information system with simple and clear structured screen layouts.

In the bank differences in semantics of users and IT professionals hinder a good mutual cooperation. Especially the abundant use of technical jargon, models, and tools raises more questions on the side of the users than answered. One of the users:

Due to the growing technical information flow, we need to have more IT knowledge to judge whether or not the IT design meets our needs. In the end it is so complicated that I often think: "probably everything is all right. ..." So I stop reading the entire report. I only focus on some passages I can understand. Often, however, at the end of the development process user tests reveal problems that we could had foreseen, when we would have understood the entire concept. But are we, users, to blame for that?

IT professionals too see this semantic problem, but often they are not able to close the communication gap. One IT professional confirmed this by stating:

It is a problem that occurs frequently and it seems to be part of the game, a characteristic of developing IT projects. It is mentioned everywhere, not only with us at the bank. The functional design report is so abstract and so far from day-to-day reality of users that they cannot judge whether or it is complete or not, or whether it matches the user specifications.

Problems concerning top-down implementation, organizational conservatism, and the incompetence to deal with semantic confusion indicate the deficit of PROMIS implementation. It appears to be impossible to consolidate PROMIS in the daily practice of IT management in the bank. Despite its promising concept the newly developed integrated approach of IT management is considered a failure.

Ongoing Processes. Nevertheless, as we notice, IT development is an ongoing process. In December 1997 the bank develops a new integrated approach, called FOCUS, which is said to be "much more based on the core principles of the integrated approach than PROMIS ever was. We expect a lot of this new method. We have learned a lot developing PROMIS.... in particular about the wrong way. Now we know better, we hope" (team member FOCUS). Apparently the organization has made a "loop backwards" reconsidering introduction, adoption, and implementation of another implication of the integrated approach of IT management.

\section{LESSONS LEARNED}

What prospects are there for applications of an integrated approach of IT management? Based on recent theories of the life cycle of management fashions, we emphasize that its success largely depends on the suc- 
cess or failure of the translation of core ideas of the integrated approach of IT management in day-to-day practices. We learn from our analysis that translation problems hinder successful application. Because looking at organizational problems from a different perspective provides us with insight in opportunities, we can transcribe these obstacles into major critical success factors. Our analysis clearly indicates that during introduction, adoption, and implementation of new ideas of IT management attention should be paid to the following in order to "make ideas work":

- To deal with the pejorative soft connotation of the integrated approach, effort should be put in successful legitimization by focusing on the strategic and organizational benefits of the introduction of the integrated approach of IT management.

- To enlarge the chances of successful introduction of the integrated approach, an active support is needed from a strong and influential external professional network.

- To ensure general acceptance of the approach by all parties involved, an active participation policy should be carried out to guarantee sufficient internal support.

- To avoid (unintentional) relabeling, all persons involved should pay attention to the sense-making process within the adoption process in order to maintain a fit between labels and contents of the application of the new approach.

- To avoid stagnation of the adoption process a sophisticated implementation strategy is required, combining top-down initiatives and bottom-up elaboration.

- To overcome organizational inertia, explicit attention should be paid to a "management of change" con- cerning the dominant views, norms, and routines accompanying the use of an integrated approach of IT management.

- To deal with semantic confusion, alertness is needed to develop a shared and common language to make the integrated approach work in practice and to use its benefits optimally.

Figure 3 is a schematic representation of critical factors of success concerning application of the integrated approach. To benefit optimally from the promising perspectives of the integrated approach of IT management, much effort must be put in dealing with these critical factors of success.

The fashion paradox, however, indicates also that, in translating the core ideas of the integrated approach into IT development practices, it is not evidently that attention will be paid to translation obstacles and critical factors of successful translation. In order to "sell" its value the approach is brought in the organization discourse as a new, inspiring, and promising concept. In so doing, the advocates focus more on its benefits and less on critical factors ("problems do not sell, opportunities do!") and that-as we argued in this article-explains both the strengths and weaknesses of the approach.

The continuously questioning of the persistency of the former technology-driven approach is a most important value of the integrated approach of IT management. We need the vision of an integrated approach of IT management to improve the day-to-day practice of developing IT, although translation obstacles make it difficult to realize its promises. Translation is not just a matter of rational calculation. Translation processes, and thus translation obstacles, are carved implicitly into the day-to-day practices of enacting, interpreting, and im-

\begin{tabular}{|c|c|c|c|}
\hline Phase & Introduction & Adoption & Implementation \\
\hline $\begin{array}{c}\text { Translation } \\
\text { Processes }\end{array}$ & Enactment & $\begin{array}{c}\text { Acceptation } \\
\text { Interpretation } \\
\text { Customization }\end{array}$ & $\begin{array}{c}\text { Cultural } \\
\text { Retention }\end{array}$ \\
\hline $\begin{array}{c}\text { Translation } \\
\text { Obstacles }\end{array}$ & $\begin{array}{c}\text { Pejorative } \\
\text { Connotation }\end{array}$ & $\begin{array}{c}\text { Insufficient Internal } \\
\text { Support } \\
\text { Lack of a } \\
\text { External Network }\end{array}$ & $\begin{array}{c}\text { Top down } \\
\text { Implementation } \\
\text { Organization } \\
\text { Culture Inertia }\end{array}$ \\
\hline $\begin{array}{c}\text { Critical } \\
\text { Success }\end{array}$ & $\begin{array}{c}\text { Legitimization } \\
\text { Factors }\end{array}$ & $\begin{array}{c}\text { Support by } \\
\text { Participation }\end{array}$ & $\begin{array}{c}\text { Strategic } \\
\text { Implementation } \\
\end{array}$ \\
& Network & $\begin{array}{c}\text { Attention for } \\
\text { Sense-making }\end{array}$ & $\begin{array}{c}\text { Management of } \\
\text { Cultural Change } \\
\text { Shared Language }\end{array}$ \\
\hline
\end{tabular}

Figure 3. Critical factors of success concerning successful application of the integrated approach of IT management. 
plementing new managerial concepts like the integrated approach of IT management. That makes it very hard to break through the naturalness of these processes. Our analysis, revealing major translation obstacles, helps to create the alertness necessary to turn these translation obstacles into critical factors of success.

\section{ACKNOWLEDGMENTS}

We would like to thank our colleagues Jos Aarts and Jos Benders and the reviewers of Failure and Lessons Learned in Information Technology Management for their stimulating comments on an earlier draft of this paper.

\section{REFERENCES}

Abrahamson, E. (1996). Management fashion. Academy of Management Review, 21(1), 254-285.

Abrahamson, E. (1997). The emergence and prevalence of employee management thetorics: The effects of long waves, labour unions, and turnover, 1875 to 1992. The Academy of Management Joumal, 40(3), 491-533.

Astley, W. G., \& Zammuto, R. F. (1992). Organization science, managers, and language games. Organization Science, 3(4), 443-460.

Avison, D. E., \& Wood-Harper, A. T. (1991). Information systems development research: An exploration of ideas in practice. The Computer Joumal, 34(2), 98-112.

Beath, C. M., \& Orlikowski, W. J. (1994). The contradictory structure of systems development methodologies: Deconstructing the ISuser relationship in information engineering. Information Systems Research, 5(4), 350-377.

Benders, J., \& Van Bijsterveld, M. J. L. (1998). Lean production in Germany: The reception of a management fashion. Paper presented at the 16th International Labour Process Conference, Manchester.

Benschop, Y., \& Doorewaard, H. (1998), Covered by equality. The gender subtext of organizations. Organization Studies, 19(5), 787805.

Bjerknes G., Ehn, P., \& Kyng, M. (1987). Computers and democracy. A Scandinavian challenge. Aldershot: Gower.

Blackler, F., \& Brown, C. (1986). Alternative models to guide the design and introduction of the new Information technologies into work organisations. Journal of Occupational Psychology, 59(4), 287-313.

Bodker, S. (1991). Through the interface-a human activity approach to user interface design. New York: Erlbaum.

Borum, F., \& Kristensen, P. H. (1989). Technological innovation and organizational change: Danish patterns of knowledge, networks and culture. Copenhagen: New Social Science Monographs.

Borum, F., \& Westenholz, A. (1995). The incorporation of multiple institutional models: Organizational field mujtiplicity and the role of actors. In R. W. Scott \& S. Christensen (Eds.), The institutional construction of organizations. International and longitudinal studies. Thousand Oaks, CA: Sage.

Bourdieu, P. (1977). Outline of a theory of practice. Cambridge: Cambridge University Press.

Brunsson, N. (1993). Trends and fashion in organizational forms. Paper presented at the 11th EGOS Colloquium, Paris.

Brunsson, N., \& Olsen, J. P. (1993). Organizational forms: Can we choose them? In N. Brunsson \& J. P. Olsen (Eds.), The reforming organization. London: Routledge.

Checkland, P. B. (198I). Systems thinking, systems practice. Chichester/London: Wiley.

Checkland, P. B., \& Holwell, S. (1998). Information, systems and information systems. Chichester/London: Wiley.

Cherrington, D. J. (1989). Organizational behavior: The management of individual and organizational performance. Boston: Allyn and Bacon.

Clegg, S. R. (1989). Frameworks of power. London: Sage.
Clegg, S. R., Chris, et al. (1996). The performance of information technology and the role of human and organizational factors. Report to the Economic and Social Research Council UK. OASIG survey. Sheffield: University of Scheffield.

Clegg, C. W., \& Kemp, N. J. (1986). Information technology, personnel where are you? Personnel Review, 15(1), 8-15.

Cooper, R. B. (1994). The inertial impact of culture on IT implication. Information \& Management, 27(1), 17-31.

Cummings, T. G., \& Worley, C. G. (1997). Organization development and change. New York: West Publishing Company.

Doorewaard, H. (1988). Management by seduction and office automation. In W. Buitelaar (Ed.), Technology and work. Aldershot: Gower.

Doorewaard, H., \& Kudsen, T. (1992). Technology and organization: An integrated approach. Paper presented at the Participatory Design Conference, Cambridge. Boston: MIT.

Doorewaard, H., \& Regtering, H. (1990). Integraal automatiseren. Deventer: Kluwer Bedrijfswetenschappen.

Dreger, J. B. (1989). Function point analysis. Englewood Cliffs: Prentice Hall.

Dunlop, Ch., \& Kling, R. (Eds.) (1991). Computerization and controversery: Value conflicts and social choices. Boston: Academic Press.

Ehn, P. (1988). Work oriented design of computer artifacts. Stockholm: Arbetslivcentrum.

Floyd, C., \& Keil, R. (1983). Adapting software development for systems design with users. In U. Briefs, C. Ciborra, \& L. Schneider (Eds.), Systems design for, with, and by the users. Amsterdam: North-Holland.

French, W. L., \& Bell, C. H., Jr. (1995). Organization development. Englewood Cliffs: Prentice Hall.

Friedman, A. L., \& Cornford, D. S. (1989). Computer systems development: History, organization and implementation. Chichester/ London: Wiley.

Greenbaum, J. (1979). In the name of efficiency. Philadelphia: Temple University.

Greenbaum, J. (1995). Windows on the workplace. Computers, jobs, and the organization of office work in the late twentieth century. New York: Monthly Review Press.

Greenbaum, J., \& Kyng, M. (1991). Design at work: Cooperative design of computer systems. New York: Erlbaum.

Grint, K. (1994). Reengineering history. Organization, J(1), 179-202.

Hammer, M., \& Champy, J. (1993). Reengineering the corporation. London: Nicolas Brealy Publishing.

Hirschheim, R. A. (1985). Office automation: Concepts, technologies and issues. Wokingham: Addison-Wesley.

Hornby, P., Clegg, C. W., Robson, J. I., MacLaren, C. R. R., Richardson, S. C. S., \& O'Brien, P. (1992). Human and organizational issues in information systems development. Behaviour \& Information Technology, /1(3), 160-174.

Jenkins, A. M., Naumann, J. D., \& Wetherbe, J. C. (1984). Empirical investigation of systems development, practices and results. Information \& Management, 7(2), 73-82.

Jones, C. (1986). Programming productivity. New York: McGrawHill.

Kieser, A. (1997). Rhetoric and myth in management fashion. Organization, 4(1), 49-74.

Latniak, E. (1995). Technikgestaltung and direct participation: German experiences in managing technological change. In J. Benders, J. De Haan, \& D. Bennett (Eds.), The symbiosis of work and technology. London: Taylor \& Francis.

Latour, B. (1986). The powers of association. In J. Law (Ed.), Power, action and belief. London: Routledge and Keegan Paul.

Lewin, K. (1951). Field theory in social science: Selected theoretical papers. New York: Harper and Row.

Lucas, H. C., Jr. (1975). Why information systems fail. New York: Columbia University Press.

Markus, M. L., \& Robey, D. (1988). Information technology and organizational change: Causal structure in theory and research. Monagement Science, 34(5), 583-598.

Mathiassen, L. (1984). Summary of the working group systems development and prototyping. In R. Budde, K. Kuhlenkamp, L. Mathiassen, \& H. Züllighoven (Eds.), Approaches to prototyping. Berlin: Springer Verlag.

Martin, J., \& McClure, C. (1983). Software maintenance. The problems and its solutions. Englewood Cliffs: Prentice Hall. 
Mumford, E. (1983). Designing human systems for new technology: The ETHICS method. Manchester: Manchester Business School.

Orlikowski, W. J. (1992). The duality of technology: Rethinking the concept of technology in organizations. Organization Science, 3(3), 398-427.

Ortmann, G. (1995). Formen der Produktion; Organisation und Rekursivität. Opladen: Westdeutscher Verlag.

Putnam, L. H., \& Myers W. (1992). Measures for excellence: Reliable software on time, within budget. Englewood Cliffs: Prentice Hall.

Ramsay, H. (1996). Managing skeptically. In S. R. Clegg \& G. Paimer (Eds.), The politics of management knowledge. London: Sage.

Rockart, J. F. (1979, April/May). Chief executives define their own data needs. Harvard Business Review.

Røvik, K. A. (1996). Deinstitutionalization and the logic of fashion. In B. Czarniawska \& G. Sevón (Eds.), Translating organizational change (pp. 139-172). Berlin: De Gruyter.

Røvik, K. A. (1998). The translation of popular management ideas: Towards a theory. Paper presented at the 14th EGOS Colloquium in Maastricht, The Netherlands, July 9-11.

Saarinen, T., \& Sääksjärvi, M. (1992). Process and product success in information systems development. Joumal of Strategic Information Systems, 1(5), 266-277.

Salzman, H., \& Rosenthal, S. (1993). Software by design: Shaping technology and the workplace. Oxford: Oxford University Press.

Sauer, C. (1993). Why information systems fail: A case study ap. proach. Henley-on-Thames: Alfred Waller.

Sauer, C. (1998). Deciding the future for IS failures-not the choice you might think. In W. L. Currie \& R. D. Galliers (Eds.), Rethinking MIS. Oxford: Oxford University Press.

SBA-Swedish Vulnerability Board and the Swedish Federation of
Data Processing Users. (1984). SBA = SarBachets Analys. Surrey: Learning Productions Ltd.

Scarborough, H., \& Corbett, J. M. (1992). Technology and organization. Power meaning and design. London/New York: Routledge.

Scott Morton, M. S. (Ed.) (1991). The corporation of the 1990s. Information technology and organizational transformation. New York Oxford: Oxford University Press.

Symon, G., \& Clegg, C. W. (1991). Technology-led change: A study of the implementation of CADCAM. Journal of Occupational Psychology, 64, 273-290.

Taylor, D. A. (1990). Object-oriented technology: A manager's guide. Alameda: Servio.

UTOPIA PROJECT. (1982). The Utopia Project: On training, technology and products viewed from the quality of work perspective. Stockholm: Utopia.

Van Bijsterveld, M. J. L. (1997). Integraal Automatiseren: de Kloof tussen Retoriek en Realiteit. Delft: Eburon.

Weick, K. E. (1979). The social psychology of organizing. Reading: Addison Wesley.

Williams, R. (1987). Democratising systems development: Technological and organisational constraints and opportunities. In G. Bjerknes, P. Ehn, \& M. Kyng (Eds.), Computers and democracy: $A$ Scandinavian challenge. Aldershot: Gower.

Yin, R. K. (1989). Case study research: Design and methods. Beverly Hills: Sage.

Zaltman, G., \& Duncan, R. (1977). Strategies for planned change. New York: Wiley.

Zelkowitz, M. V., Shaw, A. C., \& Gannon, J. D. (1979). Principles of software engineering and design. Englewood Cliffs: Prentice Hall.

Zuboff, S. (1988), In the age of the smart machine. New York: Basic Books. 